\title{
Numerical simulation with the finite element using the contact between the soil and the actively working body
}

\author{
Dan Chiorescu ${ }^{1, *}$, Esmeralda Chiorescu ${ }^{1}$, and Oana Dodun ${ }^{2}$ \\ ${ }^{1}$ University of Agronomical Sciences and Veterinary Medicine, 3, Mihail Sadoveanu Alley, 700490, \\ Iaşi, Romania \\ ${ }^{2}$ Gheorghe Asachi Tehnical University, 59 A, Dimitrie Mangeron Blvd, 700050, Iași, Romania
}

\begin{abstract}
In this present paper, because of the complexity of the system soil - agricultural machine, we will use an analytical model which respects the geometry of the active element, realising a prediction of the forces which result at the dislocation of the soil. This study analyses the behavior of the working tool, part of the soil processing machine, using the Finite Element Method (FEM) in three different stages. In the pre-processing stage, the objective was to design a three dimensional model in CATIA V5, in keeping with the geometry of the active element, represented by the Cartesian coordinates, together with a portion of the soil rendered as a parallelepiped shape. The second stage followed the introduction of conditions both for the working part, through the fastening of the plowshare frame, the moving direction and velocity, and for the soil, through the action of the cohesion and internal friction forces. In the third stage, called the processing stage, there is the simulation of the process of soil displacement done in real conditions, for various degrees of refinement of the discretization network in finite elements.
\end{abstract}

\section{Introduction}

Because agriculture brings a major contribution to the sustainable development of the economy, there exists a major demand for innovative technologies, for durable systems of the agricultural plot, which prevents or minimizes the degradation of the soil. In general, the reason for the studies done by researchers is done to evolve agricultural machines which function autonomously for the benefit of the farmers [1].

The soil is a complex environment that can be considered, for simplification purposes, as a combination of solid particles, organic matter and porous spaces that allow air breakthrough and water accumulation and movement. The share of soil particles in its volume, for an ideal productive soil, should be: $45 \%$ mineral particles, $5 \%$ organic matter, $25 \%$ porous spaces filled with water and $25 \%$ porous spaces filled with air [2].

Research has shown that about half of the energy is used for cultivating the soil. This high energy consumption is caused by the large amount of soil to be engaged during

\footnotetext{
${ }^{*}$ Corresponding author: dan chiorescu@yahoo.com
} 
cultivation because of the inefficient method of transferring energy from the working part to the soil $[3,4]$.

The main research studies have focused on the interaction between the soil and the type of work, different soils (physical and mechanical traits of the soil), the working part (shape, angle) and working conditions (working depth, cutting width, velocity).

Because of the complexity of the soil-machine system, analytical models are used, limiting the study to the geometry of the active plowshare, making a prediction of the forces resulting from engaging the soil.

The continuous development of computers combined with the improvement of the mathematical techniques and methods have lead to the occurrence of new generations of very efficient software which have succeeded in simulating various agricultural operations. The determination model of the soil-tool system to be submitted to the finite element analysis consists in passing from a continuous structure having an infinite number of points to a discrete model with finite number of points called knots, covering the model in a discretization network $[5,6]$.

The finite element method (FEM) used in the current paper analyses the interaction between the soil and the working part by studying the stress - deformation function in relation to the real working conditions. By using the finite element method, the main changes in the material structure are highlighted (the material thinning rate, the stress field, the direction of the deformations) together with the soil deformation [7].

\section{Material and method}

The programming software Ansys was used for the simulation with the finite element method, allowing the study of the behaviour of the active working part, the normal stress being analysed in real conditions, at various depths and velocities for a soil with a claysandy texture $[8,9]$.

To analyse the behaviour of the working part within the soil-tool system, using the finite element method, a tridimensional model was constructed replicating exactly the geometry of the active element while the soil was rendered through a parallelepiped. In this paper the active working part under study is a plowshare made in $3 \mathrm{~d}$ using the designing software CATIA, the file being saved with the igs extension in order to be imported. The import of the basic design of the plowshare is made in the Explicit Dynamics module.

The experiments were made in the Western Plain of Romania on a soil of the noncarbonated chernozem (black earth) type with mainly clay-sandy texture, using the PP-4-30 plow having the following technical characteristics:

- Working width on the plough-body, $b_{\mathrm{Tr}}=30 \mathrm{~cm}$; Number of plough-bodies $n_{\mathrm{Tr}}=2$;

- Plow Working width $B=b_{\operatorname{Tr}} \cdot n_{\mathrm{Tr}}=30 \cdot 2=60 \mathrm{~cm}=0.60 \mathrm{~m}$; Total mass $m=565 \mathrm{~kg}$;

- Plow weight $G_{p l}=g \cdot m=9.81 \cdot 565=5543 \mathrm{~N}$.

The physical - mechanical properties of the material of the plowshare OLC 45 under the Romanian standard STAS 880-80 and the European standard SR EN 10083-2:1995 symbolized as 1C45 in Table 1, are introduced in the pre-processing stage.

Table 1. Mechanical and physical characteristics of the 1C45 steel.

\begin{tabular}{|c|c|c|c|c|}
\hline $\begin{array}{c}\text { Steel } \\
\text { brand }\end{array}$ & $\begin{array}{c}\text { Tensile yield } \\
\text { strength } \\
\mathbf{R p}_{\mathbf{0}, 2}[\mathbf{M P a}]\end{array}$ & $\begin{array}{c}\text { Ultimate tensile } \\
\text { strength } \\
\mathbf{R}_{\mathbf{m}}[\mathbf{M P a}]\end{array}$ & $\begin{array}{c}\text { Poisson } \\
\text { Coefficient } \\
\mathbf{n}_{\text {med }}\end{array}$ & $\begin{array}{c}\mathbf{A} \\
{[\mathbf{\%}]}\end{array}$ \\
\hline $\mathbf{1 C 4 5}$ & 410 & 800 & 0.3 & 14 \\
\hline
\end{tabular}

Considering the nonlinear plastic behaviour of the Drucker Prager type of the claysandy soil, its characteristics are shown in Table 2. 
Table 2. Soil properties.

\begin{tabular}{|c|c|}
\hline Soil Properties & Corresponding Values \\
\hline Soil Type & Sandy clay \\
\hline Young's modulus of elasticity $(\mathrm{Es})$ & $19000 \mathrm{kPa}$ \\
\hline Posson's ratio $(\eta)$ & 0.3 \\
\hline Cohesion $(\mathrm{C})$ & $23 \mathrm{kPa}$ \\
\hline Internal friction angle $(\varnothing)$ & 32 \\
\hline
\end{tabular}

The simulation of the plowing process at depths between 15 and $40 \mathrm{~cm}$ is made tridimensional, taking into account only the active working part that is the plowshare. A system of coordinates is assigned to the soil, made of 3 axes: Ox, Oy and $\mathrm{Oz}$, in which the plowshare movement direction is positive along the Ox axis (Figure 1).

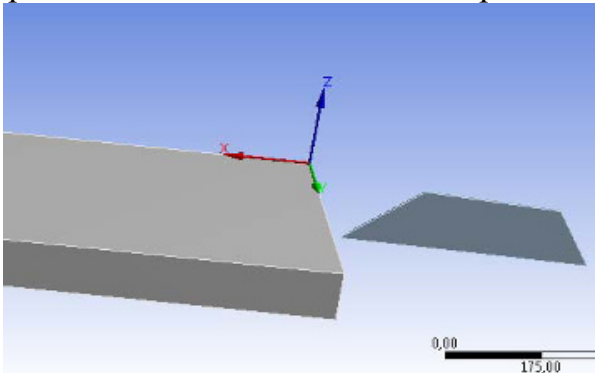

Fig. 1. The system of axes and the plowshare movement direction.

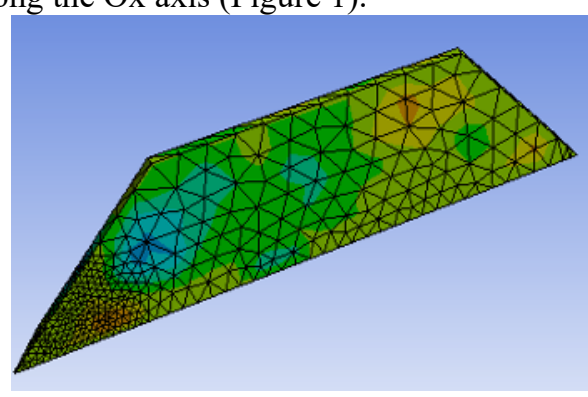

Fig. 2. The ddiscretization of the plowshare.

We are doing a tridimensional study on the unitary stresses in relation to the plowshare movement direction in the plowing process along the Ox direction for 3 velocity values $(0.50 ; 1.00 ; 1.50 \mathrm{~m} / \mathrm{s})$ at different depths $(0.18 ; 0.25 ; 0.36 ; 0.38 \mathrm{~m})$ and the 12 values of the traction resistance. The stress resistance force was established experimentally using pin transducers. It was used a VISHAY - HS 100 MG7128 type force cell of $100 \mathrm{kN}$, invertor number FO21633 - USA, calibrated on 20.09.2015. For the measurements it was used a

Table 3. Maximum and minimum normal stress at different velocities and depths.

\begin{tabular}{|c|c|c|c|c|c|}
\hline No. & $\begin{array}{l}\text { Velocity } \\
\mathbf{v}[\mathbf{m} / \mathbf{s}]\end{array}$ & $\begin{array}{c}\text { Depth } \\
\text { a }[\mathrm{m}]\end{array}$ & $\begin{array}{c}\text { Traction } \\
\text { resistance } \\
\mathbf{R}_{\mathrm{tr}}[\mathrm{N}]\end{array}$ & $\begin{array}{c}\text { Maximum } \\
\text { normal } \\
\text { stress } \\
\text { [MPa] }\end{array}$ & $\begin{array}{c}\text { Minimum } \\
\text { normal } \\
\text { stress } \\
\text { [MPa] }\end{array}$ \\
\hline 1 & \multirow{4}{*}{0.50} & 0.18 & 4806 & 52.534 & -98.763 \\
\hline 2 & & 0.25 & 6780 & 44.438 & -93.213 \\
\hline 3 & & 0.36 & 8620 & 71.544 & -94.100 \\
\hline 4 & & 0.38 & 9040 & 44.751 & -106.560 \\
\hline 5 & \multirow{4}{*}{1.00} & 0.18 & 6507 & 42.186 & -92.926 \\
\hline 6 & & 0.25 & 8850 & 43.461 & -95.585 \\
\hline 7 & & 0.36 & 9805 & 73.271 & -146.03 \\
\hline 8 & & 0.38 & 10127 & 46.154 & -93.029 \\
\hline 9 & \multirow{4}{*}{1.50} & 0.18 & 6842 & 48.752 & -92.345 \\
\hline 10 & & 0.25 & 7920 & 39.268 & -93.258 \\
\hline 11 & & 0.36 & 11860 & 245.32 & -270.71 \\
\hline 12 & & 0.38 & 12604 & 136.52 & -362.46 \\
\hline
\end{tabular}

data system consisting of a laptop and the master unit - Traveller 1, model MUT - 1, 1016$\mathrm{S}$ type with 8 SG-2 type tensometric amplifying channels with a transmission band of $1 \mathrm{kHz}$. The results were obtained on a sandy clay soil at different depths in Table 3 . 
After introducing the mechanical characteristics of the plowshare material as well as the soil properties, we need, for the simulations set, to choose the optimum discretization for the working part (plowshare) as well as the constraints within the system, according to the importance during the working process. Thus, for the whole plowshare we choose a discretization of $1 \mathrm{~mm}$, and for the tip $0.5 \mathrm{~mm}$ (Figure 2). For the soil the discretization value is $3 \mathrm{~mm}$, to shorten the time needed for cycles rolling.

One can notice following simulation that for a clay-sandy soil at a velocity $v=0.5 \mathrm{~m} / \mathrm{s}$, the maximum normal stress on OX direction is $52.534 \mathrm{MPa}$ (Figure 3), for a depth of $\mathrm{a}=0.18 \mathrm{~m}$, and $44.751 \mathrm{MPa}$ for $\mathrm{a}=0.38 \mathrm{~m}$ (Figure 4).

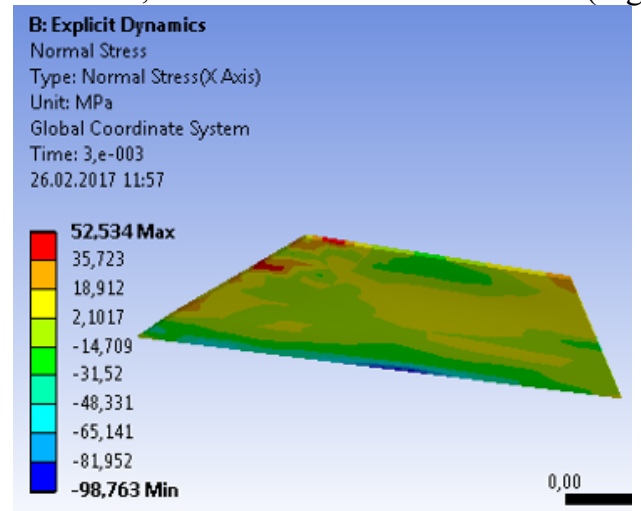

Fig. 3. Normal stress on movement direction $\mathrm{x}$, at $\mathrm{v}=0.5 \mathrm{~m} / \mathrm{s}, \mathrm{a}=0.18 \mathrm{~m}$, for clay - sandy soil.

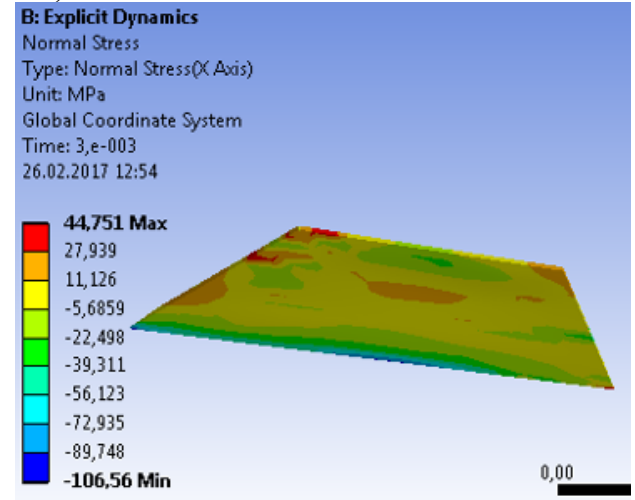

Fig. 4. Normal stress on movement direction $\mathrm{x}$, at $\mathrm{v}=0.5 \mathrm{~m} / \mathrm{s}, \mathrm{a}=0.38 \mathrm{~m}$, for clay - sandy soil.

To move the plowshare with the velocity of $1.0 \mathrm{~m} / \mathrm{s}$, the maximum normal stress is $42.186 \mathrm{MPa}$ (Figure 5) at $0.18 \mathrm{~m}$ depth, while for $0.38 \mathrm{~m}$ depth, the maximum normal stress is $46.154 \mathrm{MPa}$ (Figure 6).

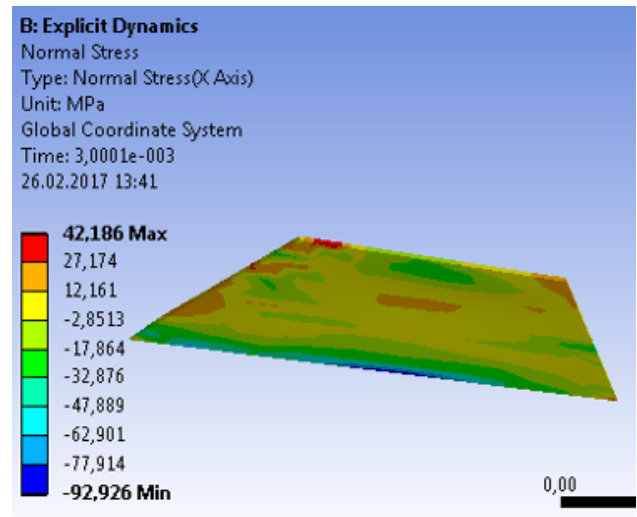

Fig. 5. Normal stress on movement direction $\mathrm{x}$, at $\mathrm{v}=1.0 \mathrm{~m} / \mathrm{s}, \mathrm{a}=0.18 \mathrm{~m}$, for clay - sandy soil.

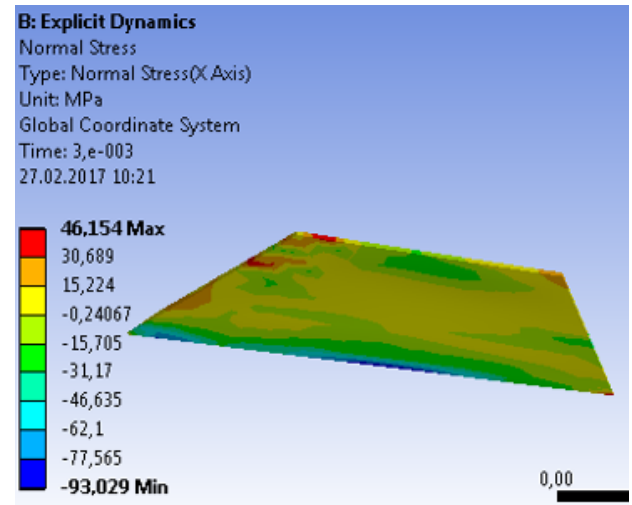

Fig. 6. Normal stress on movement direction $\mathrm{x}$, at $\mathrm{v}=1.0 \mathrm{~m} / \mathrm{s}, \mathrm{a}=0.38 \mathrm{~m}$, for clay - sandy soil.

Following the simulation of the basic process (plowing) of the clay-sandy soil for a plowshare movement velocity of $1.50 \mathrm{~m} / \mathrm{s}$, the maximum normal stress is $48.752 \mathrm{MPa}$ (Figure 7) at a depth of $\mathrm{a}=0.18 \mathrm{~m}$ and it has a value of $136.52 \mathrm{MPa}$ for a depth of $0.38 \mathrm{~m}$ (Figure 8).

The study was based on the analysis of the maximum normal stress at a depth variation of $\mathrm{a}=0.18 ; 0.25 ; 0.36 ; 0.38$, for three values of the plowshare mouvement velocity $\mathrm{v}=0.5$; $1.0 ; 1.5 \mathrm{~m} / \mathrm{s}$ (Figures 9, 10, 11). 


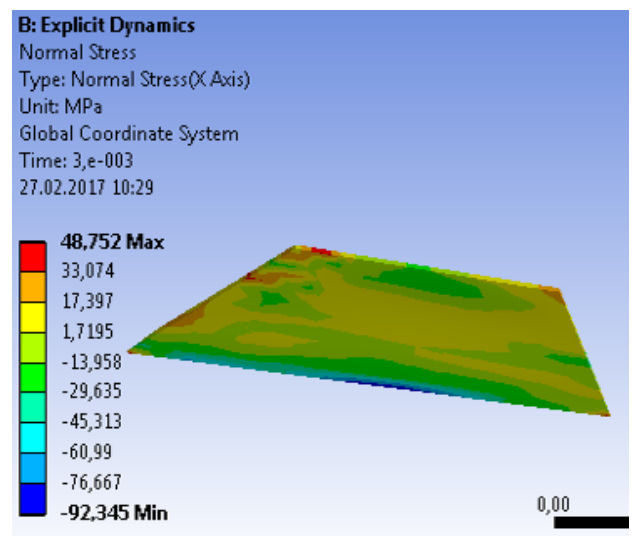

Fig. 7. Normal stress on movement direction $\mathrm{x}$, at $\mathrm{v}=1.5 \mathrm{~m} / \mathrm{s}, \mathrm{a}=0.18 \mathrm{~m}$, for clay - sandy soil.

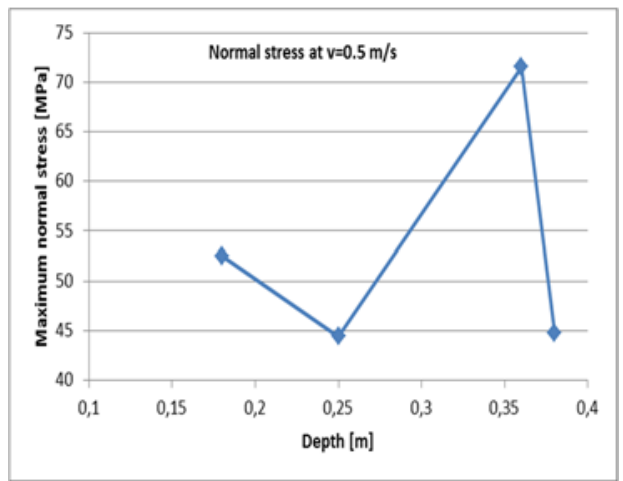

Fig. 9. Variation of the normal stress in relation to the working depth at velocity $\mathrm{v}=0.5 \mathrm{~m} / \mathrm{s}$ for clay-sandy soil.

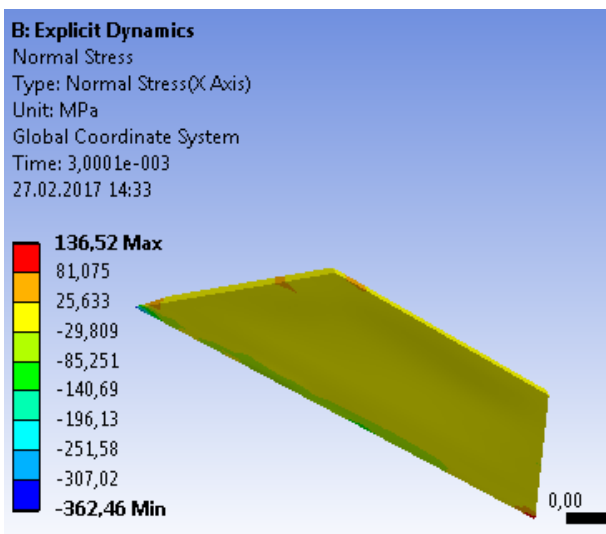

Fig. 8. Normal stress on movement direction $\mathrm{x}$, at $\mathrm{v}=1.5 \mathrm{~m} / \mathrm{s}, \mathrm{a}=0.38 \mathrm{~m}$, for clay - sandy soil.

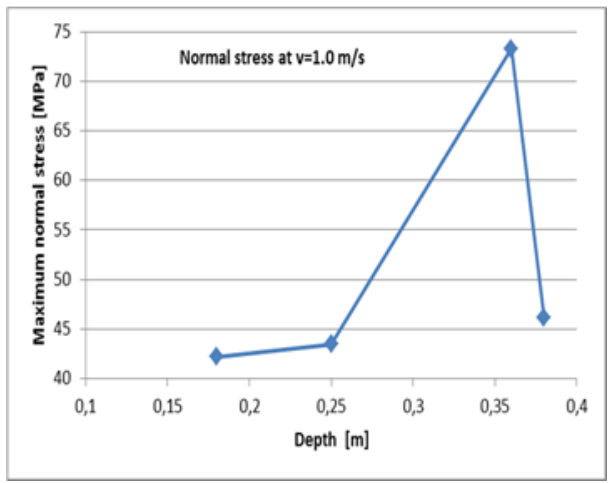

Fig. 10. Variation of the normal stress in relation to the working depth at velocity $\mathrm{v}=1.0$ $\mathrm{m} / \mathrm{s}$ for clay-sandy soil.

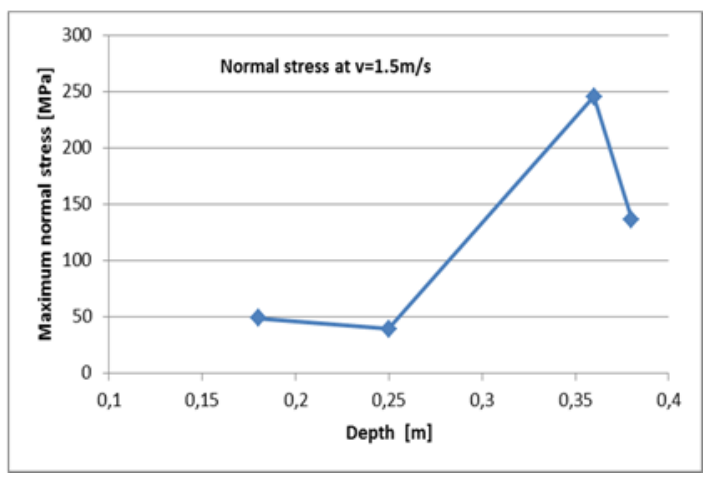

Fig. 11. Variation of the normal stress in relation to the working depth at velocity $\mathrm{v}=1.5 \mathrm{~m} / \mathrm{s}$ for clay-sandy soil.

\section{Conclusions}

A representative set of twelve problems was designed regarding the plowing process using the plowshare, differentiated through three values of movement velocity and four different depth values. 
All twelve problems concerning the soil plowing were solved though numerical simulations using the Ansys software package, employing the same refinement degree of the discretization network with finite elements in Cartesian coordinates.

Caused by the large weight of plowing machines, the soil compaction, highlighted as well by the thinning of the superficial layer, has a significant influence, especially down to $0.36 \mathrm{~m}$ depth.

Hence, an increase in the traction resistance is noticeable translated into increased stress in the working part. Between $0.36 \mathrm{~m}$ and $0.38 \mathrm{~m}$ depth, there is a decrease of the normal stress due to better aeration and a more drilling circulation of the free water in the soil.

Following simulation, we can conclude that the clay-sandy soil can receive high tensile or shear stresses due to the linking forces between the particles or between the aggregates and the particles, achieving low deformations for this type of soil.

For the analysed type of soil, the wear of the working part is evident especially at the tip and the base of the plowshare blade, the main cause being the friction with the soil.

For this reason, special measures are required to increase the durability of the active parts through various methods like coating the surface with ceramic materials based on titanium compounds.

\section{References}

1. G. Jităreanu, I. Tenu, et.all., Technologies and Machines for Mechanizing Soil Tillage in Order to Employ the Sustainable Agriculture Concept, Edp. "Ion Ionescu de la Brad" (2007)

2. A. Canarache, The physics of agricultural soil, Edp. Ceres, Bucureşţi, România (1990)

3. E. Chiorescu, D. Prepelita, St. Popescu, Envrironmental Engeneering and Management Journal, Vol.8, nr.3, 447-452, ISSN 1582-9596- Iaşi (2009)

4. E. Chiorescu, Şt. Popescu, D. Toma, Envrironmental Engeneering and Management Journal, Vol.7, nr. 6, ISSN 1582-9596, 809-813, Iasi (2008)

5. H. Bernacki, J. Haman, CZ. Kanafojski, I, Naţional Technical Information Service, Springfield, Ilinois, USA (1972)

6. H. Bentaher, A. Ibrahmi, E. Hamza, M. Hbaieb, G. Kantchev, A. Maalej, et al, Soil Till, Res. 134, 11-16 (2013)

7. R. Jafari, Proceeding F-and-B Proceedings of the 1st WSEAS International Conference on Finite Differences-Finite Elements-Finite Volumes-Boundary Elements, 122-127 (2008)

8. C. Kosmas, S. Gerontidis, M. Marathianou, B. Detsis, T. Zafiriou, W. Nan Muysen, G. Govers, T. Quin., K. Vanoost, Soil Till, Res. 58, 31-44 (2001)

9. R. Derpsch, M.A. Florentín, K. Moriya. Proyecto Conservación de Suelos MAG GTZ, San Lorenzo, 40 (2000) 